\title{
The contribution of task-related factors to ERP repetition effects at short and long lags
}

\author{
SHLOMO BENTIN and BAT-SHAHAR PELED \\ Hadassah Hospital and Hebrew University, Jerusalem, Israel
}

\begin{abstract}
Event-related potentials (ERPs) were used to assess the relative contribution of task-related decision-making processes to the repetition effect at Lags 0 and 15. Electrophysiological activity was recorded from 16 subjects in two tasks. Task A required a lexical decision: subjects were instructed to silently count infrequently occurring nonwords in a list of words and nonwords. Task B, a recognition memory task presented in four blocks, required subjects to distinguish between old and new probes in each block. Significant ERP repetition effects, equivalent in both tasks, were found at Lag 0 . In contrast, at Lag 15, the repetition effect was significant only in Task A. These results suggest that ERPs are sensitive primarily to poststimulus-identification sources of the repetition effect, such as the recovery of episodic traces related to stimulus-categorization and decision-making processes.
\end{abstract}

Task performance is improved when a stimulus has been previously encountered in the list (e.g., Clarke \& Morton, 1983; Forbach, Stanners, \& Hochhaus, 1974; Scarborough, Cortese, \& Scarborough, 1977; Winnick \& Daniels, 1970). In a typical paradigm, this repetition ef$f e c t$ is manifest in the fact that stimulus response latency is shorter and error rate is lower with the repeated presentation of the stimulus than with its initial presentation. Such a reduction has been demonstrated for lexical decision tasks (Forbach et al., 1974; Ratcliff, Hockley, \& McKoon, 1985; Scarborough et al., 1977), as well as for tasks that do not necessarily require decision making and stimulus categorization, such as the identification of perceptually degraded stimuli (Carroll \& Kirsner, 1982; Jacoby, 1983; Jacoby \& Dallas, 1981; Murrell \& Morton, 1974).

An important aspect of the repetition effect (particularly for words) is that it is relatively long lasting. In contrast to semantic priming effects, which decay very quickly (Dannenbring \& Briand, 1982; Henderson, Wallis, \& Knight, 1984; Meyer, Schvaneveldt, \& Ruddy, 1975), repetition effects remain significant after hours, days, or even longer time lags (Jacoby, 1983; Kolers, 1976; Scarborough et al., 1977). Repetition effects are also obtained with lists in which 40 to 120 unrelated items separate the initial and the repeated presentations (Feustel, Shiffrin, \& Salasoo, 1983; Moscovitch, 1985). However, the constraints on the repetition effect at short and long lags are different. At short lags, stimulus repetition improves performance in almost every task, for both familiar

\footnotetext{
This study has been supported by the Israeli Institute of Psychobiology and by the Israeli Academy of Science: The Basic Research Foundation. We thank Gregory McCarthy for his generous help, and Marta Kutas and Cyma Van Petten for useful comments. Correspondence about this paper and requests for reprints may be addressed to Shlomo Bentin, Department of Neurosciences, University of California, San Diego, La Jolla, CA 92093.
}

and unfamiliar items. In contrast, at long lags, the repetition effect depends upon both the task and the nature of the stimuli (Bentin, 1989; Bentin \& Moscovitch, 1988; Monsell, 1985; Ratcliff et al., 1985).

Lexical decision tasks have been used frequently to examine the repetition effect at short and long lags. The mechanism of the repetition effect on lexical decision, particularly at long lags, is a matter of controversy. Several plausible (and not mutually exclusive) sources have been suggested (see, e.g., Monsell, 1985, 1987): (1) a longlasting change in the accessibility of lexical representations (such as those underlying word-frequency effects), (2) facilitation of the retrieval of lexical information (such as the phonological structure of the word and its meaning), (3) episodic recognition of the probe that enhances its familiarity and induces a bias toward responding "word," and (4) recovery of an episodic trace that helps the subject remember the stimulus identity and the decision or response that was associated with it. At Lag 0 , however, we must include two more possibilities: (5) short-lived sublexical and/or lexical activation, and (6) short-lived semantic activation, whose effect on lexical decision might be either a top-down priming effect on word identification, a postlexical processing bias, or both. Many behavioral studies have been devoted to disentangling the above sources' relative contributions to the repetition effect at short and long lags (e.g., Monsell, 1985; Ratcliff et al., 1985). Recently, these efforts have been complemented by event-related potential (ERP) studies.

In the initial demonstration of ERP repetition effects, Rugg (1985) reported that waveforms elicited by the first presentation of a stimulus were relatively less positive than were those elicited by the second presentation that immediately followed the first. The divergence between the waveforms started at about $300 \mathrm{msec}$ and lasted until about $600 \mathrm{msec}$ from stimulus onset. In a more recent 
study, Rugg (1987) found a biphasic repetition effect on ERPs: There was a transient component, with an onset latency of about $200 \mathrm{msec}$ (repeated items were less positive); in addition, there was a longer, sustained effect, starting at about $300 \mathrm{msec}$, similar to that reported in his previous study. The transient component of the repetition effect was similar for words and nonwords, whereas the sustained component was greater for words than for nonwords.

Recently, Nagy and Rugg (1989) examined the influence of increasing the lag between repeated items on the ERP. They reported that the magnitude of the effect on the late component was not significantly affected by lag (up to 19 intervening items), but that the early component was evident only at zero lag. Also, Rugg and Nagy (1987) reported that the late ERP effect was considerably larger and more prolonged when elicited by orthographically legal nonwords than when elicited by orthographically illegal letter strings. On the basis of those results, Rugg (1987) suggested that the early component is related to the facilitation of prelexical processes (e.g., the identification of letters), whereas the late component is related to the accessing of lexical memory.

This interpretation of both the early and the late components, however, can be questioned on several empirical and theoretical grounds. For example, the early component of the ERP effect is not reliable (e.g., Bentin \& McCarthy, 1989; Rugg \& Nagy, 1987). Also, Bentin and McCarthy (1989) found that the late component can be elicited by repetition of both lexical and nonlexical items (faces), provided that the categorization task is sufficiently difficult. In addition, the late component is not elicited by repetition of words when the perceptual distinction between the two stimulus categories is easy (see also Rugg, Furda, \& Lorist, 1988). Thus, we need additional investigations that will enable us to characterize the transient and sustained repetition effects on ERP and will help us to understand the cognitive processes that elicit these components. To this end, the present study focuses on the late sustained component, which has been replicated in many studies, including a previous study from our laboratory (Bentin \& McCarthy, 1989).

Our objective was to assess how task-related decisionmaking processes affect the ERP manifestations of the repetition effect. Bentin and McCarthy (1989) found that, at Lag 0, the magnitude of the repetition effect on both ERP and reaction time is greatly dependent on the difficulty of the decision required by the task. In the present study, we have extended this investigation over Lag 15 . We chose Lag 15 because it is a point at which short-lasting repetition effects are no longer effective but long-lasting repetition effects in lexical decision remain large (Bentin, 1989; Bentin \& Moscovitch, 1988).

ERPs were recorded while the subjects performed two cognitive tasks. In Task A, the subjects were instructed to silently count nonwords that occasionally appeared in a list of words. Some of the words in the list were repeated at Lag 0, and some were repeated at Lag 15. Although words were not directly relevant to this task, an implicit lexical decision for each item was required. Task B was a recognition memory paradigm that did not require any categorical decision on the relevant words. The subjects were instructed to read and memorize lists of words for future recognition. Some of the words in the lists were repeated at $\mathrm{Lag} 0$, and some were repeated at Lag 15. Thus, in Task B we examined the effect of repeating stimulus identification and storage operations in the absence of any task-related decision. ERP repetition effects related to prelexical visual perception and word identification should be similar between tasks. Any difference in the repetition effects between Tasks A and B should be attributable to postidentification, task-specific processes.

\section{METHOD}

\section{Subjects}

The subjects were 24 undergraduate students ( 12 males, $12 \mathrm{fe}$ males), 22 of whom were right-handed as tested by the Edinburgh Handedness Inventory (Oldfield, 1971). The subjects either participated for course credit or were paid.

\section{Tasks}

Task A. Task A was an implicit lexical decision task. The subjects were instructed to keep a silent running count of the number of nonwords that were presented within a list of the words. There were 72 words and 24 orthographically legal nonwords in the test list. The word frequency was rated on a scale from 1 (most infrequent) to 5 (most frequent) by 50 independent judges (see Frost, Katz, \& Bentin, 1987). The rated frequency of the words ranged from 1.22 to 4.70 , with a mean of 2.96 . Each stimulus consisted of two to five letters, ' without a significant difference between words and nonwords. Twenty-four words were repeated at Lag 0, and another 24 were repeated at Lag 15; these were similar in mean word frequency and length. The resulting list of 144 stimuli was randomly ordered, with the constraints of keeping the repeated words at the predetermined lags and equally distributing the serial position of the first presentations of Lag 0 items and Lag 15 items within the list. In addition, 15 words and 3 nonwords selected from the same pool were used in a practice session.

Task B. Task B was a recognition memory task presented in four blocks. In each block, there was a study list of 30 words, followed by a set of 12 probes. A study list contained 18 different words: 6 of the 18 were repeated at Lag 0 , another 6 at Lag 15, and the last 6 occurred only once. The probes in each block were 6 words that were not included in the study list (new probes), and 6 words that were part of the study list (old probes). Among the old probes, 2 were repeated in the study list at Lag 0,2 were repeated at Lag 15, and 2 were not repeated. Thus, across blocks, the ERP elicited in the repeated and nonrepeated conditions at each lag was averaged, as in Task A, across 24 trials.

Different words were used in each block. In addition, to avoid uncontrolled repetition effects, all words in Task B were different from the words used in Task A. Across blocks, the average frequency of the words repeated at Lag 0 and their length were identical to those repeated at Lag 15 .

In addition to the test blocks, a practice block was identically constructed. The subjects were informed about the structure of the blocks. They were instructed to remember the words presented in a positive set and to categorize each probe as old or new, on the basis of whether or not it was included in the preceding set. They were also informed that words would not be repeated across blocks. 


\section{Stimuli}

All stimuli were presented at the center of a CRT screen in a display frame subtending a visual angle of $3.5^{\circ} \times 1.4^{\circ}$. The letters were from a set of standard Hebrew characters, presented in a double-height, double-width format.

\section{ERP Recordings}

EEG was recorded with Grass silver electrodes from nine scalp sites (F3, Fz, F4, Cz, P3, Pz, P4, and two temporal electrodes$\mathrm{T} 3 / 5$ [between T3 and T5] and T4/6 [between T4 and T6]according to the 10-20 system; Jasper, 1958). Linked ears were used as reference. Eye movements (EOG) were recorded bipolarly between an electrode placed on the external canthus of the left eye and an electrode placed on the supraorbital ridge, just above the center of the left eyebrow. EEG and EOG were amplified by Grass J511 amplifiers through a bandpass of $0.1 \mathrm{~Hz}-100 \mathrm{~Hz}(3 \mathrm{~dB} / \mathrm{oc}-$ tave), and sampled on-line at a rate of $250 \mathrm{~Hz}$ for $1,024 \mathrm{msec}$. Sampling started $100 \mathrm{msec}$ before stimulus onset. Single-trial data was stored on disk, and averaged off line.

\section{Procedure}

All subjects were tested on both tasks in one session. The order of the tasks was counterbalanced across subjects. Following electrode application, the subject was seated in a comfortable chair located in a sound-attenuated and electrically isolated chamber. The subject sat approximately $1 \mathrm{~m}$ away from a transparent window, through which he/she could see the CRT screen. In Task A, following instructions, the practice trials, and a short intermission, the 144 test stimuli were presented in one block. In Task B, following instructions, the practice block was presented. Following the practice block, the four test blocks were presented, with an intermission of about 1 min between blocks. The procedure used for the practice block was the same as that used for the test blocks: After the presentation of the last word in the study list, the subject was informed via intercom, and the 12 probes were presented. Reaction times and errors were monitored. In Tasks A and B, each stimulus was exposed for $1,000 \mathrm{msec}$, with 2,500-msec SOA. EEG and EOG were continuously monitored. The subjects rested for about $5 \mathrm{~min}$ between tasks.

\section{RESULTS}

The averaged waveforms elicited by repeated presentations were more positive than were those elicited by initial presentations during epochs that varied slightly with task, lag, and electrode site. Because there were no "wrong" responses, and very few artifacts, all single trials were included in the averages (see Figures 1 and 2 ). The latency and amplitude (relative to the $100-\mathrm{msec}$ baseline) of the maximum ERP repetition effect (repeatedinitial presentation) in each task, at each lag and at each electrode site, were determined for each subject separately. Averaged across electrodes, the latency of the maximum difference in Task A was $561 \mathrm{msec}$ at Lag 0 $(S D=91)$, and $651 \mathrm{msec}$ at $\operatorname{Lag} 15(S D=82)$. In Task $B$, the latency of the maximum difference was $632 \mathrm{msec}$ at $\mathrm{Lag} 0(S D=95)$, and $675 \mathrm{msec}$ at $\mathrm{Lag} 15$ $(S D=97)$.

For statistical evaluation of the ERP repetition effects, we calculated the mean amplitude of the waveforms elicited in each condition, during an epoch starting $75 \mathrm{msec}$ before and ending $75 \mathrm{msec}$ after the latency of the maximum effect. Mean, rather than maximum, amplitudes were used to control for random variability at one sampling point. A fixed time interval was used in order to avoid the comparison of areas that differed in length in different conditions. Note that the mean amplitude during a time epoch is a linear transformation of the area bounded by the waveform during that epoch; therefore, their values are equivalent.

An analysis of variance (ANOVA) with repeated measures was performed on the mean amplitude measures. The factors were task (A, B), lag $(0,15)$, repetition (first presentation, second presentation), and electrode site (F3, $\mathrm{Fz}, \mathrm{F} 4, \mathrm{~T} 3 / 5, \mathrm{Cz}, \mathrm{T} 4 / 6, \mathrm{Pz}){ }^{2}$ The degrees of freedom were adjusted wherever necessary, according to the Greenhouse-Geisser procedure to control for Type I error in repeated measure designs. The ANOVA showed a significant main effect of repetition $[F(1,23)=54.03$, $\left.M S_{\mathrm{e}}=70.44, p<.0001\right]$ and a significant main effect of electrode site $\left[F(1.8,40.8)=6.56, M S_{\mathrm{e}}=39.41\right.$, $p<.005]$. The main effects of task and lag were not significant $\left[F(1,23)=3.75, M S_{\mathrm{e}}=286.57, p<.07\right.$, and $F(1,23)<1.0$, respectively]. Another important outcome of this analysis, however, was that the interaction between task and repetition and the three-way interaction between task, repetition, and lag were significant $[F(1,23)=$ $10.56, M S_{\mathrm{e}}=52.65, p<.004$, and $F(1,23)=7.14, M S_{\mathrm{e}}$ $=78.77, p<.01$, respectively]. These interactions

\section{NonWord Detection Task}
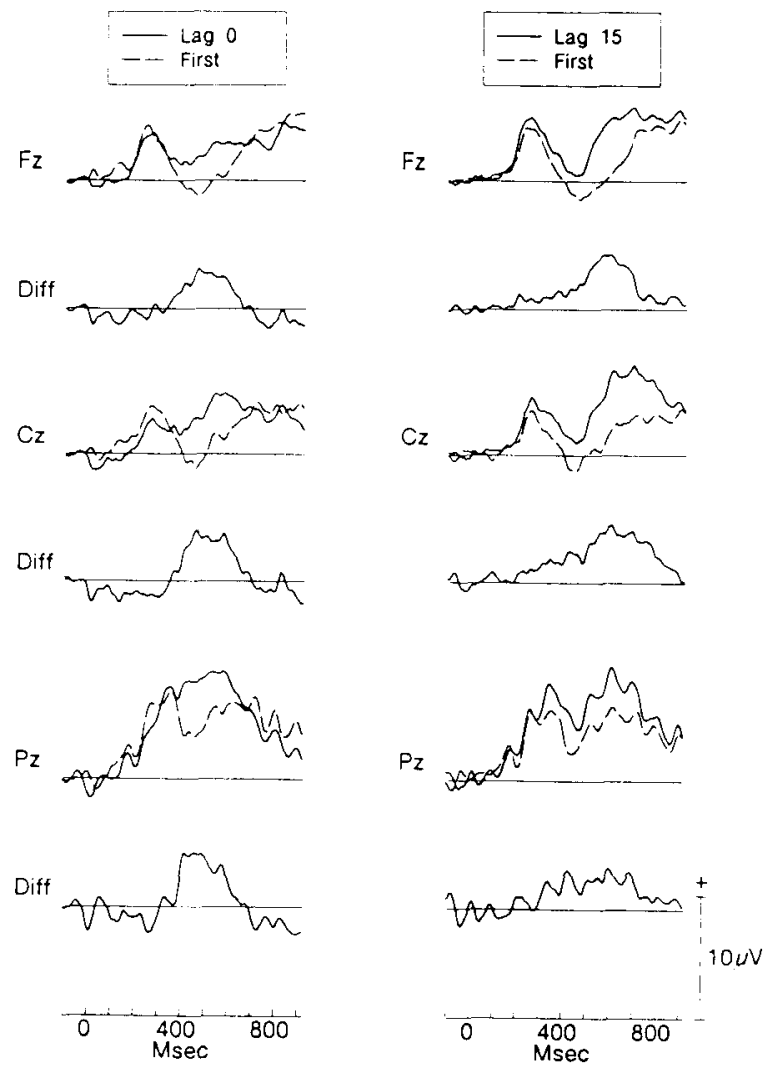

Figure 1. ERPs from the sagittal line to first and second presentations for words repeated at Lags 0 and 15 in the nonword-detection task. 


\section{Memory Task}
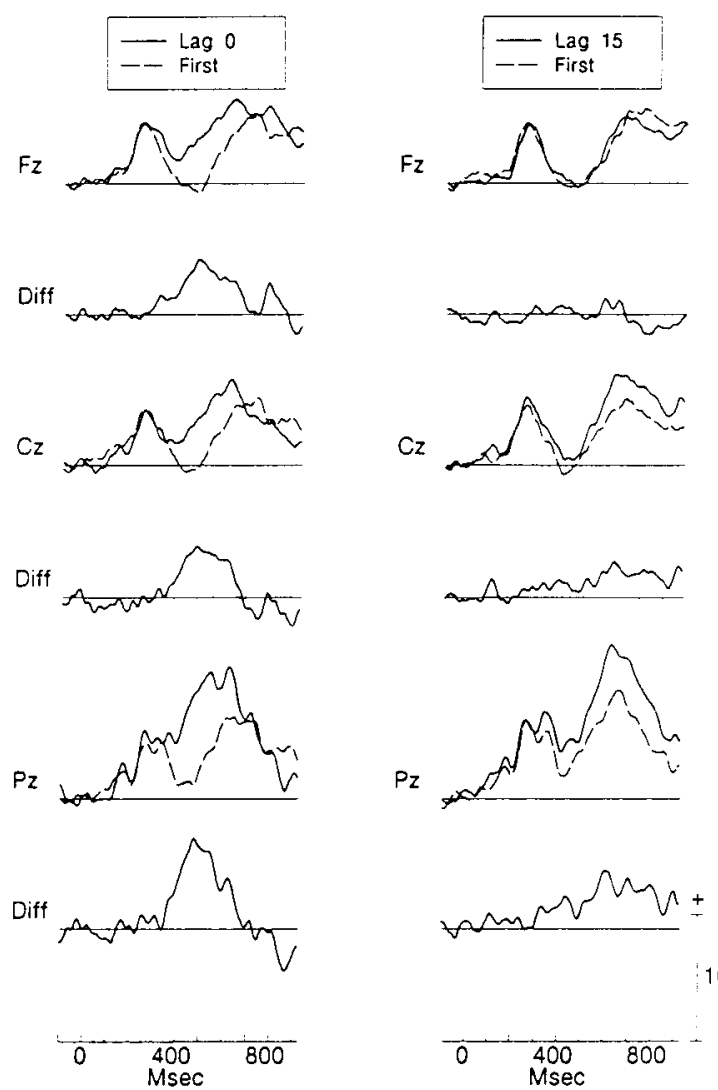

$10 \mathrm{~N}$

Figure 2. ERPs from the sagittal line to first and second presentations for words repeated at Lags 0 and 15 in the positive set of the recognition memory task.

showed that the magnitude of the ERP repetition effect in Task A was different from that in Task B, and that the lag between the first and second presentations had a different influence on the ERP repetition effect in each task. Post hoc Tukey-A tests revealed that, across lags, the repetition effect was significantly greater in Task $A$ $(4.65 \mu \mathrm{V})$ than in Task B $(2.08 \mu \mathrm{V})$. Post hoc analysis of the three-way interaction revealed that, at Lag 0 , the the repetition effect in the two tasks was similar (Task A, $4.49 \mu \mathrm{V}$; Task B, $4.50 \mu \mathrm{V}$ ). In contrast, at Lag 15 , the magnitude of the repetition effect in the lexical-decision task (Task A) was 4.82 , whereas in the recognition memory task (Task B), there was no significant repetition effect $(0.54 \mu \mathrm{V})$. $^{3}$

Because the patterns of the repetition effects in Task $A$ were different from those in Task B, the results for each task were analyzed separately. A similar three-way ANOVA with repeated measures was used for both analyses. The factors were repetition (first presentation, second presentation), lag $(0,15)$, and electrode site $(\mathrm{F3}, \mathrm{Fz}$, $\mathrm{F} 4, \mathrm{~T} 3 / 5, \mathrm{Cz}, \mathrm{T} 4 / 6, \mathrm{P} 3, \mathrm{Pz}, \mathrm{P} 4$ ). (As above, in the analysis of Task A, P3 and P4 were excluded.)

\section{Task A: "Count Nonwords"}

In Task A, there were significant main effects of repetition $\left[F(1,23)=48.54, M S_{\mathrm{e}}=74.90, p<.0001\right]$ and electrode site $\left[F(1.88,43.29)=5.54, M S_{\mathrm{e}}=22.68\right.$, $p<.01$ ]; however, the main effect of lag was not significant $[F(1,23)=0.01]$. Post hoc comparisons of the electrode sites showed that the mean amplitude was significantly greater at $\mathrm{Pz}$ than at any of the other sites, which did not differ significantly among themselves (see Table 1). Furthermore, the magnitude of the repetition effect was not equal at all electrode sites, as revealed by a significant interaction between these two factors $\left[F(2.65,61.04)=3.97, M S_{\mathrm{c}}=4.79, p<.01\right]$. Post hoc comparisons showed that the magnitudes of the repetition effects were significantly smaller at $\mathrm{Fz}$ and T4/6 than at all other electrode sites, which did not differ among themselves.

The onset of the repetition effects at Lags 0 and 15 was determined for each subject at $\mathrm{Fz}, \mathrm{Cz}$, and $\mathrm{Pz}$. The onset of the repetition effect was defined as the last point at which the difference between the waveforms elicited by the first and second presentations was zero prior to the latency of the maximum difference. An ANOVA with repeated measures was used to analyze the pattern of the onset values. The factors were lag $(0,15)$ and electrode site $(\mathrm{Fz}, \mathrm{Cz}, \mathrm{Pz})$. The ANOVA showed that the onset of the repetition effect was similar at Lags 0 and 15 (336 and $348 \mathrm{msec}$, respectively) $[F(1,23)=0.08]$, and that the difference between the onset at $\mathrm{Fz}(323 \mathrm{msec}), \mathrm{Cz}$ (325 msec), and $\mathrm{Pz}(377 \mathrm{msec})$ was not significant $\left[F(2,46)=1.83, M S_{\mathrm{e}}=25,003, p>.15\right]$.

\section{Task B: Recognition Memory}

The recognition level of all subjects was high, suggesting that the stimuli in the positive sets were well encoded (see Table 2).

To compare the percentage of errors and the RTs to the different probe categories, we used a one-way ANOVA with repeated measures, followed by Tukey $a$ post hoc comparisons. These analyses showed that the responses were slower and less accurate to negative (new) probes than to positive (old) probes [for RT analysis, $F(3,69)=3.43$, $M S_{\mathrm{e}}=1,907, p<.025$; for errors analysis, $F(3,69)=$ $\left.12.38, M S_{\mathrm{e}}=2.05, p<.001\right]$. The different categories of old probes did not differ among themselves.

The analysis of the ERP measures showed that the mean amplitude of the waveforms elicited by repetitions was

Table 1

Mean Amplitudes (in microvolts) Following First and Second Stimulus Presentation and Repetition Effects in Task A, at Seven Electrode Locations

\begin{tabular}{|c|c|c|c|c|c|c|}
\hline \multirow{3}{*}{$\begin{array}{l}\text { Electrode } \\
\text { Site }\end{array}$} & \multicolumn{3}{|c|}{ Lag 0} & \multicolumn{3}{|c|}{ Lag 15} \\
\hline & \multicolumn{2}{|c|}{ Exposure } & \multirow{2}{*}{$\begin{array}{l}\text { Repetition } \\
\text { Effect }\end{array}$} & \multicolumn{2}{|c|}{ Exposure } & \multirow{2}{*}{$\begin{array}{l}\text { Repetition } \\
\text { Effect }\end{array}$} \\
\hline & First & Second & & First & Second & \\
\hline F3 & 1.3 & 6.3 & 5.0 & 1.3 & 7.1 & 5.8 \\
\hline $\mathrm{Fz}$ & 0.3 & 3.8 & 3.5 & 0.7 & 5.1 & 4.4 \\
\hline F4 & 1.0 & 5.8 & 4.8 & 1.3 & 7.1 & 5.8 \\
\hline $\mathrm{T} 3 / 5$ & 0.7 & 5.6 & 4.9 & 0.8 & 6.3 & 5.5 \\
\hline $\mathrm{Cz}$ & 0.8 & 5.7 & 4.9 & 0.9 & 6.4 & 5.5 \\
\hline $\mathrm{T} 4 / 6$ & 2.1 & 5.3 & 3.2 & 1.3 & 4.2 & 2.9 \\
\hline $\mathrm{Pz}$ & 4.2 & 9.2 & 5.0 & 3.6 & 7.5 & 3.9 \\
\hline
\end{tabular}


Table 2

Reaction Times and Percentage of Errors for Each Category of Probe in Task B

\begin{tabular}{lcccc}
\hline & \multicolumn{3}{c}{ Old Stimuli } & \\
\cline { 2 - 4 } & \multicolumn{2}{c}{ Repeated } & $\begin{array}{c}\text { Not } \\
\text { Repeated }\end{array}$ & $\begin{array}{c}\text { New } \\
\text { Stimuli }\end{array}$ \\
\cline { 2 - 5 } & Lag 0 & Lag 15 & 677 & 714 \\
$M$ & 685 & 676 & 687 & 15.8 \\
SEM & 17.8 & 17.5 & 16.8 & 3.75 \\
\% of Errors & 2.31 & 1.14 & 1.97 & \\
\hline
\end{tabular}

Table 3

Mean Amplitudes (in microvolts) Following First and Second Stimulus Presentation and Repetition Effects in Task B, at Nine Electrode Locations

\begin{tabular}{|c|c|c|c|c|c|c|}
\hline \multirow{3}{*}{$\begin{array}{c}\text { Electrode } \\
\text { Site }\end{array}$} & \multicolumn{3}{|c|}{ Lag 0} & \multicolumn{3}{|c|}{ Lag 15} \\
\hline & \multicolumn{2}{|c|}{ Exposure } & \multirow{2}{*}{$\begin{array}{c}\text { Repetition } \\
\text { Effect }\end{array}$} & \multicolumn{2}{|c|}{ Exposure } & \multirow{2}{*}{$\begin{array}{c}\text { Repetitio } \\
\text { Effect }\end{array}$} \\
\hline & First & Second & & First & Second & \\
\hline F3 & 3.4 & 8.9 & 5.5 & 6.5 & 5.2 & -1.3 \\
\hline $\mathrm{Fz}$ & 2.6 & 7.5 & 4.9 & 5.4 & 4.2 & -1.2 \\
\hline F4 & 3.0 & 8.6 & 5.6 & 6.9 & 5.1 & -1.8 \\
\hline $\mathrm{T} 3 / 5$ & 3.0 & 6.9 & 3.9 & 5.2 & 5.6 & 0.4 \\
\hline $\mathrm{Cz}$ & 3.1 & 6.9 & 3.8 & 5.2 & 5.6 & 0.4 \\
\hline$T 4 / 6$ & 2.2 & 5.7 & 3.5 & 3.0 & 3.8 & 0.8 \\
\hline P3 & 3.1 & 5.8 & 3.7 & 5.0 & 5.4 & 0.4 \\
\hline $\mathbf{P z}_{\mathbf{z}}$ & 4.6 & 9.0 & 4.4 & 8.0 & 9.4 & 1.4 \\
\hline P4 & 3.3 & 6.6 & 3.3 & 5.6 & 6.1 & 0.5 \\
\hline
\end{tabular}

significantly more positive than that elicited by initial presentations $\left[F(1,23)=15.44, M S_{\mathrm{e}}=55.9, p<.001\right]$. Additionally, the main effect of the electrode site $\left[F(2.59,59.56)=4.16, M S_{\mathrm{e}}=29, p<.02\right]$ was significant, but the main effect of lag was not $[F(1,23)=$ 0.52 ] (see Table 3 ). In contrast to the results of Task A, the interaction between the effects of repetition and of lag in Task B was significant $\left[F(1,23)=5.87, M S_{\mathrm{e}}=174\right.$, $p<.025]$, as was the three-way interaction between lag, repetition, and electrode site $\left[F(3.59,82.61)=4.78, M S_{e}\right.$ $=5.6, p<.0025]$. Post hoc analyses revealed that the repetition effect in Task $B$ was significant at Lag 0 $(p<.01)$, but not at Lag 15. Post hoc analyses of the three-way interaction revealed that the interaction between the effects of lag and repetition was more conspicuous at the frontal sites than at all other sites.

The onset of the repetition effect at Lag 0 was calculated for Task B as it was for Task A. The onsets at Fz, $\mathrm{Cz}$, and $\mathrm{Pz}$ were 348, 296, and $355 \mathrm{msec}$, respectively. An ANOVA showed that the onset of the repetition effect was not significantly different at the different electrode sites $[F(2,46)=0.55]$. The onset of the repetition effect at Lag 0 in Task B was also compared with the onset of the repetition effect at Lag 0 in Task A. A task $\times$ electrode site ANOVA showed that the onsets were not affected by task $[F(1,23)=0.01]$ or by electrode site $\left[F(2,46)=2.10, M S_{\mathrm{e}}=22844, p>.13\right]$. The interaction between the two factors also was not significant $[F(2,46)=0.71]$.

\section{Early Effects}

To examine the possibility that stimulus repetition has had an effect during earlier time epochs, we compared the waveforms elicited by initial and repeated presentations of words during a period starting at stimulus onset and ending at the onset of the late-repetition effect (as defined above). First, we looked for the latency and amplitude of the maximal absolute difference during this epoch. This analysis was performed within each subject, in each task and at each repetition lag. We assessed the statistical significance of the differences, using the same fourfactors ANOVA design that was used for the analysis of the late component. Moreover, because Rugg (1987) had reported that the duration of the early component is much shorter than that of the late component, we calculated the mean amplitude during an epoch of only $50 \mathrm{msec}$, which encompassed the latency of the individual peak difference. Note that this procedure maximized the likelihood of obtaining significant differences. As reported by Rugg (1987), the mean amplitude elicited by repetitions $(1.17 \mu \mathrm{V})$ was numerically smaller than the mean amplitude elicited by first presentations $(1.76 \mu \mathrm{V})$. However, ANOVA revealed that this difference was not statistically significant $\left[F(1,23)=3.29, M S_{\mathrm{e}}=35.6, p>.08\right]$. The effect of repetition during the early epoch did not interact with any of the other factors.

\section{DISCUSSION}

In the present study, we examined the pattern of repetition effects in two tasks, neither of which required an overt response. In Task $A$, the subjects made lexical decisions; in Task B, the repeated words were identified and stored for future recognition, but no decision was required. Similar and significant repetition effects were found in both tasks at Lag 0 . In contrast, with 15 intervening items between the two presentations, the effect of repetition was significant only in the lexical decision task (Figure 3).

The absence of long-lasting ERP repetition effects in Task B is an interesting finding, because task-related decision processes have previously been shown not to be a necessary condition for obtaining long-lasting behavioral repetition effects (e.g., Jacoby, 1983; Murrell \& Morton, 1974). This dissociation suggests that the ERPs, at least in the present study, were sensitive to only a subset of the sources that contribute to the repetition effect on behavior. However, this limited sensitivity of the ERP to repetition can be used in such a way as to enable us to disentangle its different sources and to examine them separately. At this stage, however, we still need to relate the modulation of ERPs in repetition paradigms to specific sources of the repetition effect. In what follows, our results are discussed with this goal in mind.

The present data do not reveal the precise cognitive mechanism that is reflected by the ERP repetition effect at Lag 0. In Task A, the onset of the repetition effect was unaffected by lag. We agree with Rugg et al. (1988) that, at these onsets, the ERP repetition effect was too late to coincide with the onset of the stimulus-identification process. ${ }^{4}$ Therefore, we assume that our ERP repetition effects were not related to either short lived sublexical 


\section{REPETITION EFFECTS IN TWO TASKS}

MEMORY

NONWORD

DETECTION
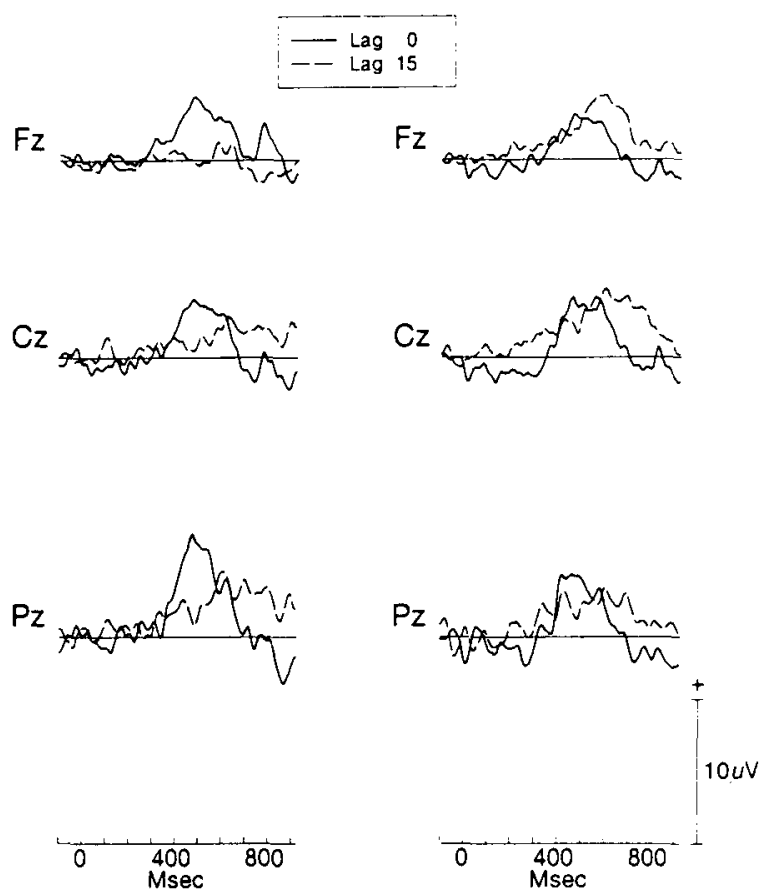

Figure 3. Repetition effects at Lag 0 compared with those at Lag 15 in the nonword-detection and recognition memory tasks.

activation or a long-lasting change in the accessibility of lexical representations (cf. Morton, 1979, 1982). It seems more plausible that the ERP effects reflect the consequences of stimulus repetition on postlexical access processes, such as lexical retrieval, encoding of information in short-term memory (STM), and recovery of episodic traces. Of course, we have no direct evidence in support of this assumption, but we can speculate that when a word is repeated at Lag 0 , the previous presentation is still available in STM. Therefore, there are certain processes that the subject does not have to repeat.

The absence of repetition effects at Lag 15 in the recognition memory task suggests that at least some of the sources of the repetition effect that are reflected in ERPs are related to the recollection of the decision-making episode. Therefore, our results support an episodic memory contribution to the repetition effect, without, of course, discounting the contribution of other sources, such as long-lasting facilitation of lexical access (for a strong episodic view, see Feustel et al., 1983; Jacoby, 1983; Jacoby \& Brooks, 1984; Jacoby \& Hayman, 1987; and for an alternative view, see Monsell, 1985, 1987; Morton, 1982). However, the nature of the episodic trace whose recovery produces the repetition effect is not immediately evident. Clearly, the duration of the repetition effect in the present study was not determined solely by the strength of the memory traces of repeated words. Recall that, in the lexical decision task, the repeated stimuli were words that the subjects were instructed to ignore, whereas, in Task B, the subjects were explicitly required to memorize the repeated stimuli. Moreover, the recognition performance in the recognition task suggests that memory for the positive sets was quite high. Therefore, we cannot account for the longer lasting repetition effects in the present study by assuming that words in Task A were memorized better than those in Task B. Rather, we are led to conclude that the different time courses of the repetition effects should be accounted for by the fact that the task-related procedures required by Task A were different from those required by Task $B$.

The two tasks used in the present study differed primarily with respect to postidentification processes. In Task A, following stimulus identification (or as a result of it), the subjects were required to make a lexical decision. In Task B, the subjects were not required to make a decision while they were learning the words in the positive set. Although both stimulus storage and lexical decision are subject to strategic control, it may be that decision strategies are more susceptible to repetition effects than are storage strategies. This might be due to the fact that, if subjects remember (explicitly or implicitly) the decision made at the first encounter with the repeated stimulus, new decision-making processes become redundant to a great extent. In contrast, the operations involved in storing a word in memory might be facilitated by repetition but, particularly when the stimulus is no longer in STM, they might have to be repeated nonetheless. Therefore, it is possible that the episodic trace responsible for part of the long-lasting repetition effects reflects primarily strategic factors in task performance that are more characteristic of tasks that require a categorical decision.

The relation between the ERP repetition effects and other ERP modulations is not clear. Originally, the ERP repetition effect was viewed in the context of N400 research, because this effect (at least at Lag 0 ) was considered to be an extension of the semantic priming effect and was thought to reflect similar mechanisms (Rugg, 1985). However, recent data has demonstrated that the ERP repetition effects and ERP semantic priming effects are dissociable in latency, suggesting that they are related to different cognitive mechanisms (Rugg, 1987). Moreover, repetition effects at long lags cannot be accounted for in terms of semantic priming (e.g., Bentin \& Feldman, in press; Henderson et al., 1984). Finally, Bentin and McCarthy (1989) reported significant ERP repetition effects in categorization tasks that required neither semantic nor lexical processing. Therefore, we see no sufficient reason to posit that our ERP repetition and N400 effects are related to the same cognitive mechanism.

An alternative view is to assume that the ERP repetition effect is related to the $\mathrm{P} 300$ component. A late positivity was observed in both tasks, particularly at the parietal sites. This positivity was more pronounced in response to the repeated presentations than to the first presenta- 
NonWord Detection Task

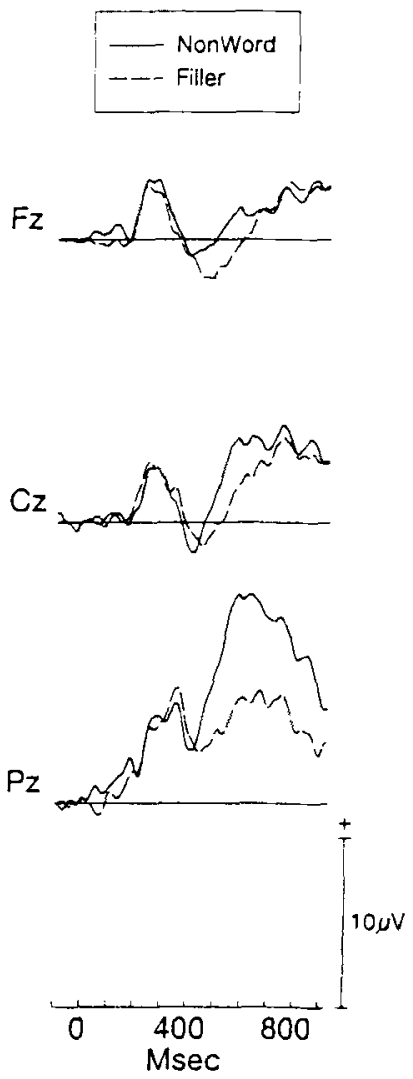

Figure 4. P300 components related to the "oddball" rare nonwords relative to the ERPs to fillers in the "count nonwords" task.

tions of the stimuli. The posterior-anterior distribution of this positivity is, indeed, similar to that of $\mathrm{P} 300$. However, it is not clear why repetitions should have evoked a P300 component. Recent accounts for the generation of P300 suggest that it reflects the updating of schemata in working memory (e.g., Donchin, 1981). In the traditional "oddball" paradigm, the counted infrequent stimuli are assumed to cause updating of working memory because they are subjectively unexpected. This subjective probability effect was also found in our experiment when the responses to the counted nonwords were compared with the responses to fillers (Figure 4).

Early studies, however, have reported that $\mathrm{P} 300$ may also be evoked by uncounted-stimulus categories if their probabilities in the list are very low (Ritter, Vaughan, \& Costa, 1968; Squires, Petuchowski, Wickens, \& Donchin, 1977). In the present study, the subjects might have considered a repetition as a distinct, obtrusive event, which appeared only $34 \%$ of the time in Experiment 1 and only $40 \%$ of the time in Experiment 2 (if the relative frequencies of repetitions at Lags 0 and 15 are to be added). However, this hypothesis can be seriously challenged. First, in studies in which nontarget stimuli have elicited P300, subjects had been instructed to ignore the stimuli but they had not been assigned any explicit task, and the objective probability of the P300-eliciting events was ex- tremely low. In the majority of studies in which subjects have actively performed a task, no P300 was elicited by the ignored stimuli (for a review of P300 and task relevance, see Donchin, Ritter, \& McCallum, 1978). Second, if the act of repetition per se was experienced as an "oddball," unexpected, and obtrusive event, then the same repetition effect should have been observed in both tasks at both lags. It therefore seems that, although there are reasons to relate the present late-latency repetition effect to a P300 component, a simple and direct relation is not appropriate. Research in which the probability of a repetition is manipulated independently of task is required before more definite conclusions can be drawn.

In conclusion, our data suggest that ERP modulations reflect primarily postidentification effects of stimulus repetition. Moreover, they provide evidence that recovery of an episodic trace, probably related to decision making and/or stimulus categorization, contributes to the longlasting repetition effect. In addition to these decisionmaking processes, long-lasting repetition effects probably also stem from nonepisodic changes in the accessibility of words (Monsell, 1985). This source, however, was not evident in the ERP in the present study. The relatively early ERP component described by Rugg (1987) might reflect this source, but additional work is necessary to determine the circumstances that elicit this component and its precise cognitive origin.

\section{REFERENCES}

Bentin, S. (1989). Orthography and phonology in lexical decision: Evidence from repetition effects at different lags. Joumal of Experimental Psychology: Learning, Memory, \& Cognition, 15, 61-72.

Bentin, S., \& Feldman, L. B. (in press). The contribution of morphemic and semantic relatedness to repetition priming at short and long lags: Evidence from Hebrew. Quarterly Journal of Experimental Psychology.

Bentin, S., MCCarthy, G. (1989, June). Stimulus and task on ERP-repetition effects at lag 0 . Paper presented at The 9th Evoked Potential International Conference (EPIC IX), Holland.

BENTIN, S., \& Moscovitch, M. (1988), The time course of repetition effects for words and unfamiliar faces. Journal of Experimental Psychology: General, 117, 148-160.

Carroll, M., \& Kirsner, K. (1982). Context and repetition effects in lexical dexision and recognition memory. Joumal of Verbal Learning \& Verbal Behavior, 21, 55-69.

ClaARE, R., \& MORTON, J. (1983). Cross-modality facilitation in tachistoscopic word recognition. Quarterly Joumal of Experimental Psychology: Human Experimental Psychology, 35A, 79-96.

Dannenbring, G. L., \& Briand, K. (1982). Semantic priming and the word repetition effect in a lexical decision task. Canadian Journal of Psychology, 36, 435-444.

Donchin, E. (1981). Surprise! Surprise? Psychophysiology, 18, 493-513.

Donchin, E., Ritter, W., \& McCallum, W. C. (1978). Cognitive psychophysiology: The endogenous potentials of the ERP. In E. Callaway, P. Tueting, \& S. H. Koslow (Eds.), Event-related potentials in man (pp. 349-411). New York: Academic Press.

Feustel, T. C., Shiffrin, R. M., \& Salasoo, A. (1983). Episodic and lexical contributions to the repetition effect in word identification. Journal of Experimental Psychology: General, 112, 309-346.

Forbach, G. B., StanNers, R. F., \& Hochiaus, L. (1974). Repetition and practice effects in a lexical decision task. Memory \& Cognition, 2, 337-339.

Frost, R., Katz, L., \& Bentin, S. (1987). Strategies of visual word 
recognition and orthographic depth: A multi-lingual comparison. Journal of Experimental Psychology: Human Perception \& Performance, $15,104-115$.

Henderson, L., Wallis, J., \& KNIGHT, D. (1984). Morphemic structure and lexical access. In H. Bouma \& D. Bouwhuis (Eds.), Attention and performance: $X$. Control of language processes (pp. 211226). Hillsdale, NJ: Earlbaum.

JACOBY, L. L. (1983). Perceptual enhancement: Persistent effects of an experience. Joumal of Experimental Psychology: Learning, Memory, \& Cognition, 9, 21-38.

JACOBY, L. L., \& BRoOKS, L. R. (1984). Nonanalytic cognition: Memory, perception and concept learning. In G. Bower (Ed.), The psychology of learning and motivation (Vol. 18, pp. 1-47). New York: Academic Press.

JACOBY, L. L., \& DALLAS, M. (1981). On the relationship between autobiographical memory and perceptual learning. Journal of Experimental Psychology: General, 110, 306-340.

JACOBY, L. L., \& HAYMAN, G. A. (1987). Specific visual transfer in word identification. Journal of Experimental Psychology: Learning, Memory, \& Cognition, 13, 456-463.

JASPER, H. H. (1958). The ten-twenty electrode system of the International Federation. Electroencephalography \& Clinical Neurophysiology, 10, 371-375.

KOLERS, P. A. (1976). Reading a year later. Journal of Experimental Psychology: Human Learning \& Memory, 2, 554-565.

Meyer, D., SchVaneveldt, R., \& Ruddy, M. (1975). Loci of contextual effects on visual word recognition. In P. Rabbitt \& S. Dornic (Eds.), Attention and performance (Vol. 5, pp. 98-118). New York: Academic Press.

Monsell, S. (1985). Repetition and the lexicon. In A. W. Ellis (Ed.), Progress in the psychology of language (Vol. 2, pp. 147-196). Hillsdale, NJ: Earlbaum.

Monsell, S. (1987). Nonvisual orthographic processing and the orthographic input lexicon. In M. Coltheart (Ed.), Attention and performance. XII: The psychology of reading (pp. 299-323). Hillsdale, NJ: Erlbaum.

MorTon, J. (1979). Facilitation in word recognition: Experiments causing change in the logogen model. In P. A. Kolers, M. Wrolstal, \& H. Bouma (Eds.), Processing of visible language (pp. 259-268). New York: Plenum.

Morton, J. (1982). Disintegrating the lexicon: An information processing approach. In J. Mehler, E. C. T. Walker, \& M. Garrett (Eds.), Perspectives on mental representation (pp. 89-110). Hillsdale, NJ: Erlbaum.

Moscovitch, M. (1985). Memory from infancy to old age: Implications for theories of normal and pathological memory. Annals of the New York Academy of Sciences, 444, 78-96.

MURRELl, G., \& MoRTON, J. (1974). Word recognition and morphemic structure. Journal of Experimental Psychology, 102, 963-968.

NAGY, M. E., \& RUGG, M. D. (1989). Modulation of event-related potentials by word repetition: The effects of inter-item lag. Psychophysiology, 26, 431-436

OLDFIELD, R. C. (1971). The assessment and analysis of handedness: The Edinburgh Inventory. Neuropsychologia, 9, 97-113.

Ratcliff, R., Hockley, W., \& McKoon, G. (1985). Components of activation: Repetition and priming effects in lexical decision and recognition. Journal of Experimental Psychology: General, 114, 435-450.
Ritter, W., Vaughan, H. G., \& Costa, L. D. (1968). Orienting and habituation to auditory stimuli: A study of short-term changes in averaged evoked responses. Electroencephalography \& Clinical Neurophysiology, 25, 550-556.

RuGG, M. D. (1985). The effects of semantic priming and word repetition on event-related potentials. Psychophysiology, 22, 642-647.

RUGG, M. D. (1987). Dissociation of semantic priming word and nonword repetition effects by event-related potentials. Quarterly Journal of Experimental Psychology, 39A, 123-148.

RugG, M. D., Furda, J., \& LORIST, M. (1988). The effects of task on the modulation of event-related potentials by word repetition. Psychophysiology, 25, 55-63.

RugG, M. D., \& NAGY, M. E. (1987). Lexical contribution to nonwordrepetition effects: Evidence from event-related potentials. Memory \& Cognition, 15, 473-481.

Scarborough, D. L., Cortese, C., \& Scarborough, L. H. (1977) Frequency and repetition effects in lexical memory. Journal of Experimental Psychology: Human Perception \& Performance, 3, 1-17.

Squires, K., Petuchowski, S., Wickens, C., \& Donchin, E. (1977). The effects of stimulus sequence on event-related potentials: A comparison of visual and auditory sequences. Perception \& Psychophysics, 22, 31-40.

Winnick, W. A., \& Daniels, S. A. (1970). Two kinds of response priming in tachistoscopic recognition. Journal of Experimental Psychology, 84, 74-81.

\section{NOTES}

1. Note that, in Hebrew, vowels are not represented in regular print; therefore, those words were equivalent to three- to six-letter words in English.

2. Due to a technical problem, the responses at P3 and P4 in Task A were not reliable.

3. Choosing different time epochs for calculating the mean amplitude of the waveforms for each subject might have increased the probability of finding significant differences among conditions. We believe that this method emphasized the real effects of the experimental conditions, which were reflected at different latencies in different subjects. Nevertheless, to control for any possibility of artifactual significance, we have compared those results to an ANOVA of the mean amplitudes calculated during a fixed period of $150 \mathrm{msec}$ that encompassed the mean peak (across subjects) of the repetition effect. The results of this analysis were similar to those reported in the text: The main effect of repetition was significant $\left[F(1,23)=11.2, M S_{\mathrm{e}}=89.7, p<.003\right]$. The interactions between task and repetition and the three-way interaction between task, repetition, and lag were also significant $\left[F(1,23)=8.79, M S_{\mathrm{e}}=79.3\right.$, $p<.007$, and $F(1,23)=4.05, M S_{\mathrm{e}}=117.6, p<.057$, respectively]

4. Note that, although the early-onset repetition effect was not significant $(p>.08)$ in the present experiment, the difference between the waveforms was in the direction reported by Rugg (1987)-that is, the mean amplitude of the waveforms elicited by repetitions was smaller than that elicited by first presentations. Undoubtedly, this phenomenon requires additional investigation.

(Manuscript received December 15, 1988; revision accepted for publication November 21,1989 .) 